\title{
ORGANIZAC̣ÃO CURRICULAR NA PERSPECTIVA FREIRE-CTS: PROPÓSITOS E POSSIBILIDADES PARA A EDUCAÇÃO EM CIÊNCIAS
}

\author{
ELIANE DOS SANTOS ALMEIDA ${ }^{*}$ \\ https://orcid.org/0000-0002-8798-051X \\ SIMONI TORMÖHLEN GEHLEN" ** \\ https://orcid.org/0000-0002-9786-3392
}

RESUMO: Em um processo formativo de professores, balizado na Investigação Temática, investigaram-se os propósitos educacionais durante a seleção dos conteúdos programáticos para construção da Rede Temática. Para tal, foram analisadas videogravações de um curso, que possibilitou o estabelecimento de três categorias, baseadas em uma matriz de referência sobre Ciência-TecnologiaSociedade (CTS), quais sejam, o desenvolvimento de: a) percepções entre o conhecimento científico e o cotidiano do educando; b) questionamentos de situações locais; e c) compromissos sociais. A identificação destes propósitos corrobora para a defesa de que a Investigação Temática pode nortear a construção de currículos humanizadores, isso porque possibilita a autonomia e engajamento dos educandos e educadores diante de demandas sociais e a articulação entre os processos de concepção e execução de currículos.

Palavras-chave: Educação CTS. Formação de Professores. Paulo Freire.

\section{ORGANIZACIÓN CURRICULAR EN LA PERSPECTIVA FREIRE-CTS: PROPÓSITOS Y POSIBILIDADES PARA LA EDUCACIÓN EN CIENCIAS}

RESUMEN: En un proceso formativo de profesores, basado en la Investigación Temática, se investigaron los propósitos educacionales durante la selección de los contenidos programáticos para la construcción de la Red Temática. Para ello, se analizaron grabaciones de video de un curso, que posibilitó establecer tres categorías, basadas en una matriz de referencia sobre Ciencia-TecnologíaSociedad (CTS), a saber, el desarrollo de: a) percepciones entre el conocimiento científico y el cotidiano del

\begin{tabular}{r|} 
*Doutoranda em Educação em Ciências \\
pela Universidade de Brasilia (UnB). \\
E-mail: < almeida-eliane@hotmail.com >. \\
\\
**Doutora em Educacãa \\
Científica e Tecnológica pela \\
Universidade Federal de Santa \\
Catarina (UFSC). Professora do \\
Departamento de Ciências Exatas e \\
Tecnológicas e do Programa de \\
Pós-Graduação em Educação em \\
Ciências da Universidade Estadual \\
de Santa Cruz (UESC), Ilhéus/BA. \\
Coordenadora do Grupo de Estudo e \\
Pesquisa sobre Abordagem Temática no \\
Ensino de Ciências (GEATEC/UESC). \\
E-mail: < stgehlen@gmail.com $>$.
\end{tabular}

*Doutoranda em Educação em Ciências E-mail:< almeida-eliane@hotmail.com>

Doutora em Educação Tecnológicas e do Programa de Pós-Graduação em Educação em Ciências da Universidade Estadual de Santa Cruz (UESC), Illhéus/BA. Coordenadora do Grupo de Estudo e Ensino de Ciências (GEATEC/UESC). -mail:<stgehlen@gmail.com>.

I Universidade de Brasília, Brasília, DF - Brasil.

II Universidade Estadual de Santa Cruz, llhéus, BA - Brasil. 
educando; b) cuestionamientos de situaciones locales; y c) compromisos sociales. La identificación de estos propósitos corrobora la defensa de que la Investigación Temática puede orientar la construcción de currículos humanizadores, pues posibilita la autonomía y el compromiso de los educandos y educadores delante de las demandas sociales y la articulación entre el proceso de elaboración y ejecución de currículos.

Palabras clave: Educación CTS. Formación de Profesores. Paulo Freire.

\section{CURRICULAR ORGANIZATION IN THE FREIRE-CTS PERSPECTIVE: PURPOSES AND POSSIBILITIES FOR SCIENCE EDUCATION}

ABSTRACT: In a teacher training process, balanced in Thematic Research, the educational purposes were investigated during the selection of syllabus for the construction of the Thematic Network. With this aim, we analyzed video recordings of a course, which allowed the establishment of three categories, based on a reference matrix on Science-Technology-Society (CTS), which are, the development of: a) perceptions between knowledge scientific and daily life to do educating; b) questioning of local situations; and c) social commitments. The identification of these corroborated purposes for the defense of Thematic Investigation may allow the creation of humanizing curriculums, because this enables the autonomy and engagement of students and educators in the face of social demands and articulation between the processes of conception and execution of curriculums.

Keywords: STS Education. Teacher Training. Paulo Freire. 


\section{INTRODUÇÃO}

No Brasil diversos trabalhos têm discutido articulações entre a Educação CTS e os pressupostos educacionais freireanos, apontando convergências e complementariedades para uma educação humanizadora em prol da superação das desigualdades sociais (AULER, 2002, 2018; AULER; DELIZOICOV, 2006; SANTOS, 2008; STRIEDER, 2012; AULER; DELIZOICOV, 2015). Um ponto de articulação entre estas perspectivas de educação é a Abordagem Temática, ${ }^{1}$ que geralmente está presente em práticas educacionais críticas.

$\mathrm{Na}$ educação freireana, os temas são obtidos mediante a Investigação Temática que é um processo que busca o desvelamento e a transformação da situação existencial do povo oprimido. A Investigação Temática foi sistematizada por Delizoicov (1991) para o contexto do ensino de Ciências e compreende cinco etapas: 1) levantamento preliminar das condições da comunidade por meio de conversas com o povo e fontes secundárias (dados escritos); 2) análise das informações e escolha das codificações envolvendo as contradições sociais; 3) diálogos descodificadores com a comunidade para legitimação de situações-limite, ${ }^{2}$ que são sintetizadas em Temas Geradores; 4) Redução Temática que consiste no estudo sistemático e interdisciplinar do tema, selecionando conteúdos, conhecimentos científicos e ações necessárias para compreendê-lo e; 5) desenvolvimento em sala de aula.

Em relação ao conteúdo programático, Freire (1987) defende que este deve ser organizado a partir da realidade do educando, refletindo o conjunto de suas aspirações e contradições sociais, caso contrário, a educação pode contribuir para a manutenção da cultura do silêncio e dominação. Contudo, segundo Roso e Auler (2016), as práticas educacionais CTS que buscam articulação com Paulo Freire têm ignorado a Investigação Temática, desconsiderando temáticas da realidade do educando. Além disso, também existe um reducionismo metodológico em relação à Abordagem Temática, ou seja, há uma compreensão que reduz a mesma a uma metodologia, em vez de compreendê-la como uma forma de reestruturação curricular (MUENCHEM; AULER, 2007; HUNSCHE; AULER, 2009; ROSO et al., 2015; ROSO; AULER, 2016).

A fragilização de propostas curriculares pode ocorrer devido ao fato de muitas pesquisas em ensino de Ciências se preocuparem em discutir formas de como ensinar os conteúdos programáticos, sem questionar a seleção e o papel destes conteúdos já estabelecidos (STRIEDER, 2012). Para Roso e Auler (2016), este problema pode ser superado por meio da Investigação Temática, visto que "a concepção curricular experenciada por Freire, via investigação temática, faz com que o fazer educacional incida sobre 'o quê?' ensinar e o 'por quê?' ensinar' (p. 381). Já na educação CTS, estas perguntas podem ser respondidas com base na matriz proposta por Strieder (2012), uma vez que a matriz sistematiza as diversas abordagens e propósitos educacionais das produções CTS no Brasil, apontando limitações e potencialidades. As discussões tecidas na matriz podem contribuir para a superação de reducionismos presentes no contexto educacional e para uma compreensão mais crítica das relações entre Ciência, Tecnologia e Sociedade. 
Para melhor sistematizar e organizar o conteúdo programático, no processo de Investigação Temática, Silva (2004) elaborou a Rede Temática como aporte teórico-metodológico para o desenvolvimento do processo de Redução Temática - quarta etapa da Investigação Temática. Esta Rede auxilia a articulação da visão de mundo dos educandos com os conhecimentos historicamente sistematizados necessários para desvelar a sua situação existencial, representando de forma relacional as diferentes concepções dos sujeitos envolvidos na construção da prática educativa (SILVA, 2004).

Assim, o objetivo deste estudo é investigar os propósitos educacionais de professores e pesquisadores durante a construção da Rede Temática, no sentido de subsidiar a construção de currículos humanizadores na perspectiva FreireCTS. Ressalta-se que a Rede Temática foi realizada no contexto de um processo formativo de professores da Educação de Jovens e Adultos (EJA), balizado na Investigação Temática. Este estudo é um recorte da dissertação de mestrado de Almeida (2018), na qual a autora buscou caracterizar o processo de Investigação Temática de modo coerente com a articulação Freire-CTS, tendo como parâmetro a Matriz de Referência CTS.

\section{PRESSUPOSTOS DA EDUCAÇÃO HUMANIZADORA DE PAULO FREIRE E SUA ARTICULAÇÃO COM A EDUCAÇÃO CTS}

Para Paulo Freire (1987, p. 116), “a educação autêntica não se faz de A para B ou de A sobre B, mas de A com B, mediatizados pelo mundo". Isto é, a educação libertadora não pode ser pensada e desenvolvida exclusivamente pelos educadores, mas em comunhão com os educandos, tendo como incidência da ação a sua realidade existencial concreta. Esse processo é fundamentado no diálogo entre educador e educando, sendo que para o autor é necessário que o diálogo comece na busca do conteúdo programático, em torno do que ensinar.

[...] dialogicidade começa, não quando o educador-educando se encontra com os educandos-educadores em uma situação pedagógica, mas antes, quando aquele se pergunta em torno do que vai dialogar com estes. Esta inquietação em torno do conteúdo do diálogo é a inquietação em torno do conteúdo programático da educação (FREIRE, 1987, p. 47).

Nessa concepção de educação, os conteúdos programáticos não devem ter fim em si mesmos, mas auxiliar na compreensão crítica da realidade e na superação das contradições sociais. Neste processo é preciso considerar os conhecimentos prévios dos educandos, a valorização da sua cultura é essencial para a sua humanização.

Auler (2002) compreende que na sociedade atual uma leitura crítica do mundo, conforme prevê Freire, requer uma compreensão crítica da relação entre Ciência, Tecnologia e Sociedade. No processo de desvelamento da realidade em prol da emancipação social dos educandos, o autor constata a necessidade 
da problematização dos mitos: superioridade dos modelos de decisões tecnocráticas, perspectiva salvacionista/redentora atribuida à Ciência-Tecnologia (CT) e determinismo tecnológico. Esses mitos constituem compreensões ingênuas sobre CTS e podem ser considerados situações-limites de acordo com a perspectiva freireana, visto que endossam a concepção da neutralidade da CT, alimentam o modelo tradicional/ linear de desenvolvimento ${ }^{3}$ e fragilizam os processos participativos, impedindo a compreensão crítica da realidade.

Em análise das produções CTS no Brasil e Espanha, Strieder, BravoTorija e Gil-Quilez (2017) identificaram que nestes países as discussões sobre as implicações sociais da CT são tratadas com pouca criticidade e de forma superficiais, especificamente nas propostas didáticas desenvolvidas em sala de aula. As autoras sinalizam a necessidade de se abordar nas aulas e na formação dos docentes as insuficiências da Ciência para compreensão e transformação da realidade, a necessidade de adequações sociais das tecnologias às necessidades regionais e a participação no âmbito das esferas políticas, dado que essas discussões têm permanecido apenas no campo teórico.

Roso (2017) defende que as adequações sociais das tecnologias ocorram por meio da construção de outro modelo de CT, como as tecnologias sociais, por entender que as tecnologias convencionais estão vinculadas aos pressupostos capitalistas. Este redirecionamento das atividades científicas-tecnológicas pode ser realizado com o auxílio da Investigação Temática, que identifica demandas sociais, muitas vezes negligenciadas pelos interesses da classe hegemônica, que podem ser inseridas nos currículos escolares e nas agendas de pesquisas em CT (AULER; DELIZOICOV, 2015).

As diversas abordagens e propósitos educacionais sobre CTS identificadas nas pesquisas brasileiras foram sistematizadas em uma matriz proposta por Strieder (2012) e Strieder e Kawamura (2017). As discussões tecidas pelas autoras apontam as potencialidades e limitações das abordagens e propósitos CTS e auxiliam na reflexão sobre "para que ensinar" e "o que ensinar" na Educação Científica com enfoque CTS. Segundo as autoras, a Matriz (Figura 1) colabora para a implementação de práticas de ensino CTS envolvendo dimensões atualizadas de aspectos da função social da Ciência, da Tecnologia e da participação social; contribui na definição/seleção de elementos a serem priorizados em práticas escolares e possibilita resgatar lacunas e discussões esquecidas ao longo da trajetória das pesquisas sobre CTS. 
Figura 1. Matriz de Referência CTS

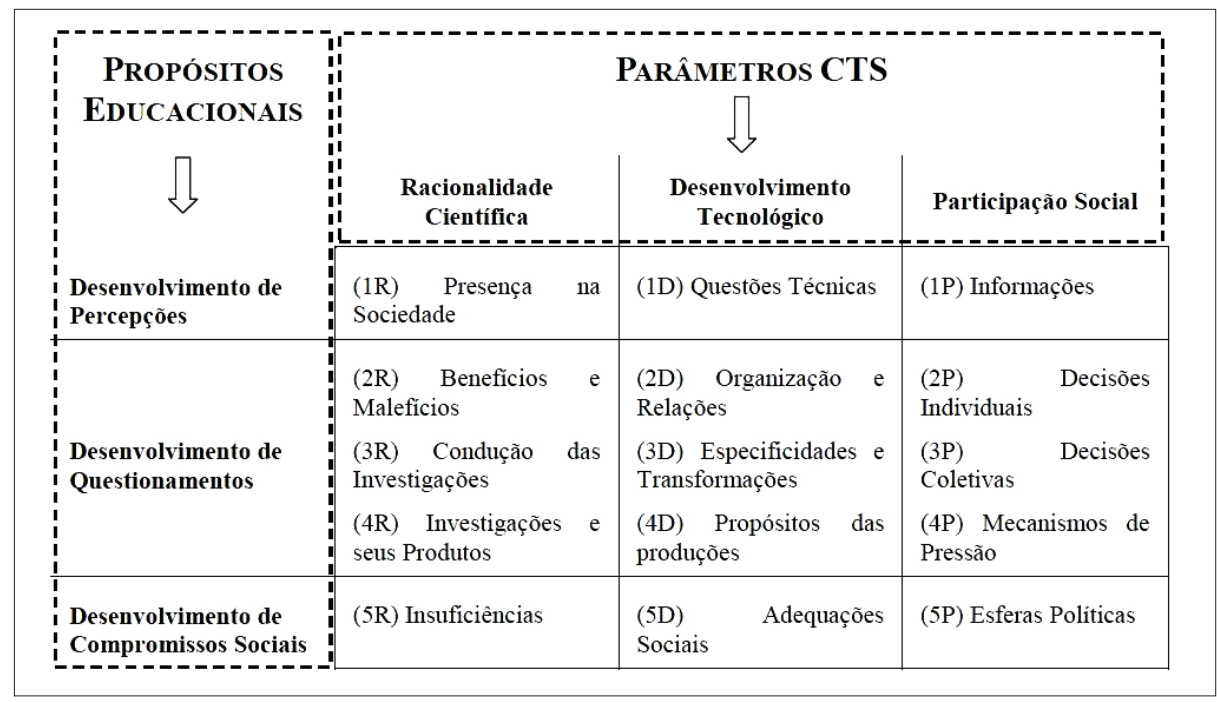

Fonte: Strieder e Kawamura (2017, p. 49).

As abordagens CTS foram sistematizadas por Strieder (2012) a partir dos parâmetros racionalidade científica, desenvolvimento tecnológico e participação social, que representam as interfaces da Ciência, Tecnologia e Sociedade. De acordo com a autora, cada parâmetro possui cinco abordagens, apresentadas em nível crescente de criticidade. Os propósitos educacionais consistem no desenvolvimento de: percepsões entre o conhecimento científico e o contexto de vida dos educandos, por meio da abordagem de aspectos relacionados à ciência, à tecnologia e/ou à sociedade; questionamentos sobre as implicações sociais da CT, objetivando à formação cidadã e a utilização responsável dos aparatos tecnológicos e; compromisso social diante de problemas relacionados a Ciência, Tecnologia e Sociedade, buscando o encaminhamento destes e a definição de novos rumos para a sociedade.

Ressalta-se que esta matriz foi validada por Strieder (2012) sendo evidenciada sua potencialidade na análise e caracterização da produção C'TS brasileira. Entretanto, ela vem sendo utilizada em diferentes contextos que envolvem a análise de: componentes curriculares em cursos de formação de professores (MATOS, 2014), concepções de licenciados em Física sobre as inter-relações CTS (DECONTO; CAVALCANTI; OSTERMANN, 2016); propostas didáticas (CARDOSO; ABREU; STRIEDER, 2016), produções CTS ibero-americanas (STRIEDER; BRAVO-TORIJA; GIL-QUILEZ, 2017) e processo de Investigação Temática para caracterizar a natureza de um Tema Gerador pautado nos pressupostos FreireCTS (ALMEIDA, 2018). No presente estudo, utiliza-se a matriz para investigar os propósitos educacionais dos professores e pesquisadores durante o processo de Redução Temática, especificamente no desenvolvimento da Rede Temática.

A Rede Temática foi elaborada por Silva (2004) e, em síntese, constitui duas partes: a base e o topo. $\mathrm{Na}$ base dispõem-se as falas significativas da comunidade, que legitimam as situações-limite, expressas no Tema Gerador. No topo da Rede, 
localizam-se as visões dos educadores, com os elementos da organização social que julgam ser necessários para entender a problemática. Assim, para Silva (2004) a Rede "por um lado, explicitam-se os limites explicativos da comunidade e, por outro, quais deverão ser os tópicos abordados para 'desembaraçar' as visões" (p. 249). Dessa forma, "a rede temática é uma tentativa de registrar o diálogo reflexivo e analítico entre os olhares e linguagens, entre pensamentos e concepções de realidade, uma primeira aproximação consciente entre essas diferentes representações coletivas" (SILVA, p. 235).

O topo da Rede temática possui também o contratema - síntese da visão dos educadores - que é uma antítese do Tema Gerador. Todo esse processo de construção da Rede é norteado por uma questão geradora, que ajuda a problematizar a realidade. Para Silva (2004), a Rede possibilita a compreensão das dimensões micro e macro da organização social. A dimensão micro é representada na visão da comunidade e a dimensão macro é representada por meio da visão dos educadores que buscam estabelecer relações socioculturais e socioeconômicas em função das necessidades/demandas da comunidade local. Fonseca (2017), com base em Silva (2004), sistematizou essa organização da Rede Temática apresentada na Figura 2.

Figura 2. Síntese da Rede Temática baseada em Silva (2004)

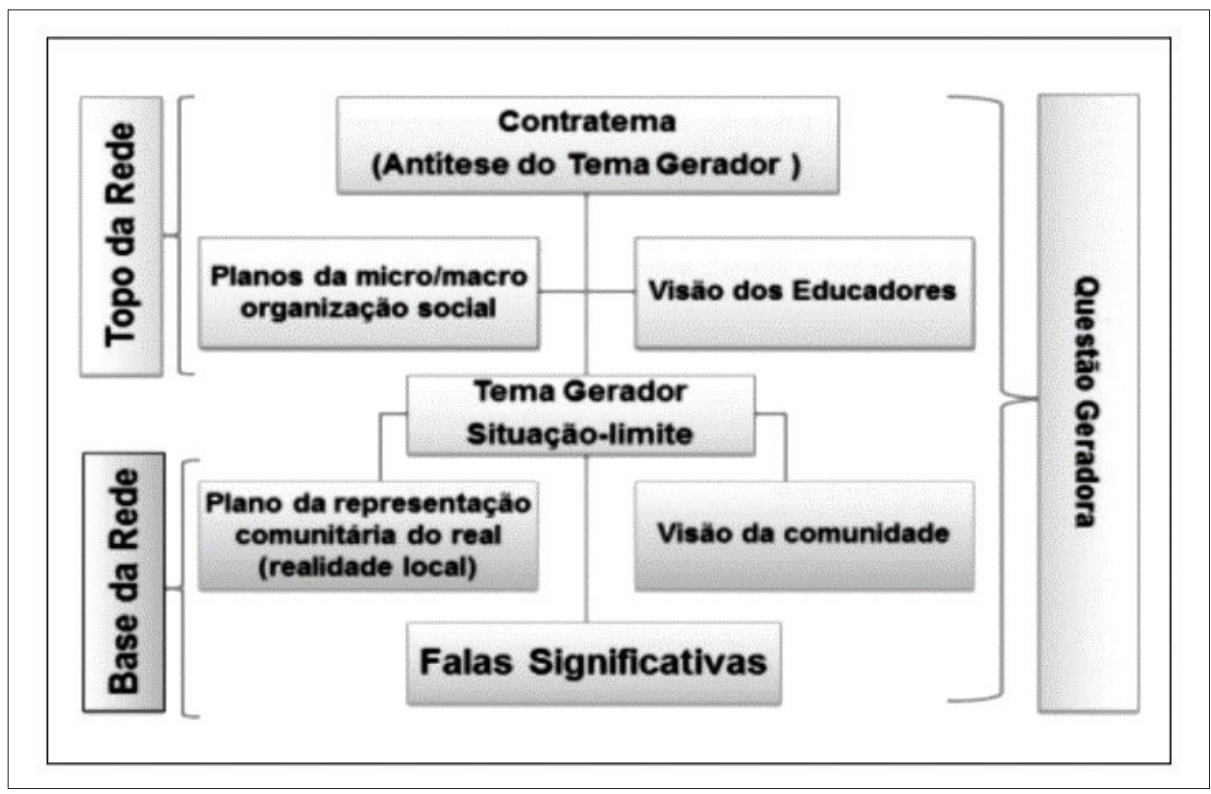

Fonte: Fonseca (2017, p. 89).

Ressalta-se que a elaboração da Rede Temática demanda uma articulação entre as diversas áreas do conhecimento, visto que o Tema Gerador em sua natureza, requer uma visão da totalidade, para seu desvelamento e ação social engajada, portanto só pode ser compreendido por meio da congregação dos diferentes campos do saber, da comunhão com os diferentes especialistas (FREIRE, 1987). 
Para o autor,

[...] os temas que foram captados dentro de uma totalidade, jamais serão tratados esquematicamente. Seria uma lástima se, depois de investigados na riqueza de sua interpenetração com outros aspectos da realidade, ao serem "tratados", perdessem esta riqueza, esvaziando-se de sua força, na estreiteza dos especialismos (FREIRE, 1987, p.66).

Em concordância, Silva (2004) ressalta que se deve ter cuidado para que os Temas Geradores não sejam trabalhados como se fossem "mais um tópico descritivo de conteúdo escolar transmitido de forma tradicional e linear a partir da análise unidirecional da realidade local realizada pelos educadores" (p. 211). Essa concepção reducionista sobre a Abordagem Temática é um desafio apontado por alguns trabalhos, como Hunsche e Auler (2009) e Roso et al. (2015). Estes trabalhos analisaram como os professores em formação inicial organizavam as atividades pautadas na Abordagem Temática e evidenciaram que os professores mesmo tendo embasamento teórico continuavam com a ideia de temas como metodologia para motivar os alunos e para abarcar os conteúdos programáticos. Nesse sentido, o objetivo deste estudo é investigar os propósitos educacionais de professores e pesquisadores durante a Redução Temática, no sentido de subsidiar a construção de currículos humanizadores na perspectiva Freire-CTS.

\section{ENCAMINHAMENTOS METODOLÓGICOS}

Este estudo foi realizado no contexto de um processo formativo de professores, promovido pelo Grupo de Estudo sobre Abordagem Temática no Ensino de Ciências (GEATEC/UESC), ${ }^{4} \mathrm{em}$ parceria com os educadores que atuam na EJA, no Colégio Estadual Jorge Calmon, localizado no município de Ilhéus. Este processo formativo ocorreu no período de setembro a novembro de 2016, com carga horária total de 40 horas, distribuídas em 08 encontros e foi organizado por meio de aspectos da Investigação Temática (SOUSA et al., 2014), apresentados de forma detalhada em Almeida (2018) e compreenderam, em síntese, as seguintes etapas:

1) Aproximações iniciais com a comunidade escolar e local: realizou-se o estudo da comunidade de Olivença, por meio de visitas, fotografias, videogravações, conversas com moradores e pesquisas nos blogs e sites da região.

2) Apresentação de situações-problema para a comunidade local e escolar: foram identificados problemas de silenciamento e medo dos moradores ao falar sobre a violência, exploração desenfreada de areia etc., os quais foram codificados e apresentados para a comunidade (educandos, educadores e representantes do poder público da cidade de Ilhéus).

3) Legitimação da Hipótese: foram realizadas três codificações (vídeo, relatos impressos e portfólio) e três descodificações (apresentação do vídeo para os educadores, agrupamentos dos relatos impressos por meio de uma dinâmica baseada na 
Análise Textual Discursiva (ATD) (MORAES; GALIAZZI, 2011) e apresentação do portfólio para a comunidade). Desses processos legitimou-se a situação-limite revelada na acomodação e aceitação da violência e extração desenfreada de areia, expressa no Tema Gerador: "Olivença: eu vivo em um paraíso esquecido".

4) Organização da programação curricular: por meio da Rede Temática (SILVA, 2004) organizou-se os conhecimentos científicos, conteúdos e ações necessárias para a superação das situações-limite, posteriormente estes conhecimentos foram agrupados em causas, consequências e possíveis alternativas para as problemáticas identificadas via Investigação Temática, de acordo com o Ciclo Temático (FONSECA, 2017) e, por fim, elaborou-se o plano de ensino compreendendo três unidades: identidade histórica de Olivença; impactos socioambientais; e infraestrutura e economia. Nestas unidades foram incorporadas algumas discussões da Matriz de referência CTS (STRIEDER, 2012).

Vale ressaltar que o distrito de Olivença, antes da colonização do Brasil, era habitado pelos povos indígenas. Atualmente ainda há índios nesta região, que vivem em conflito com os fazendeiros e donos de areais. Em Olivença existem vários areais (legais e ilegais), onde são retiradas areias para a construção civil. Olivença é uma zona de veraneio, com praias, rios, florestas, águas hidrominerais, sendo considerada a única estância hidromineral situada na faixa litorânea do Brasil, contudo vem sofrendo com problemas de poluição das águas e desmatamento.

Participaram da pesquisa todos os professores da EJA, inclusive o vicediretor do Colégio Estadual Jorge Calmon, totalizando sete participantes, com formação específica nas seguintes áreas: Matemática, Química, Física, Letras, Ciências Biológicas, História e Geografia. Conforme já mencionado, este processo formativo foi desenvolvido em parceria com pesquisadores do GEATEC. Especificamente, foram três pesquisadoras responsáveis pelo planejamento e desenvolvimento do processo formativo, uma doutora em Educação Científica e Tecnológica e duas mestrandas em Educação em Ciências. Para evitar a identificação desses sujeitos, utilizou-se sistemas alfanuméricos da seguinte forma: P1, P2 ,.., Pn (Professor) e PQ1, PQ2 ..., PQn (Pesquisador).

As informações foram obtidas mediante videogravações do processo formativo de professores e analisadas por meio da ATD (MORAES; GALIAZZI, 2011). Esta consiste em um processo de construção de compreensões por meio de uma sequência de três componentes: i) desmontagem dos textos para obtenção das unidades de significado, que consistiu nos recortes das partes das videogravações pertinentes à pesquisa; ii) estabelecimento de relações entre as unidades de significado para compreender como estas podem ser reunidas/categorizadas. Neste estudo as categorias foram definidas a priori e correspondem aos propósitos educacionais definidos por Strieder (2012), quais sejam: a) desenvolvimento de percepções, b) desenvolvimento de questionamentos e c) desenvolvimento de compromisso social e; iii) captação do novo emergente, que resulta na construção de metatextos sobre os propósitos educacionais dos professores e pesquisadores evidenciados na elaboração da Rede Temática. 


\section{PROPÓSITOS EDUCACIONAIS PRESENTES NA REDE TEMÁTICA}

A Rede Temática (Figura 03 e 04) foi realizada com os educadores da EJA do Colégio Estadual Jorge Calmon. Para uma melhor compreensão, Silva (2004) sugere que a Rede seja lida da base (Figura 03) para o topo (Figura 04). Na base da Rede estão as falas significativas de moradores, educandos e representantes do poder público do município de Ilhéus, que representam a compreensão da comunidade sobre a realidade em que vivem. Essas falas são significativas porque "trazem a denúncia de algum conflito ou contradição vivenciados pela comunidade local e que expressa uma determinada concepção, uma representação do real" (SILVA, 2004, p, 56).

No topo da Rede, a questão geradora "Como fomentar a cultura de participação na comunidade de Olivença visando à construção de uma identidade socioambiental?" orientou os professores das diversas áreas de conhecimento na seleção de conhecimentos, conteúdos e ações necessárias para superação da situação-limite: "falta de valoriz̧ação da identidade socioambiental de Olivença", que sintetiza as necessidades expressas no Tema Gerador: "Olivença: eu vivo em um paraíso esquecido". O contratema: "Identidade e pertencimento: agentes transformadores da comunidade de Olivença" sintetiza as concepções das educadoras presente no topo da Rede.

Ressalta-se que na base da Rede as falas estão interligadas por meio de setas, que evidenciam as relações existentes entre as situações apresentadas. As situações-limites se apresentam em meio a uma multiplicidade de problemas interrelacionados. Nesse exercício de buscar compreendê-las, os sujeitos se aproximam da dimensão da totalidade, da relação local-global. O mesmo acontece no topo da Rede, para a compreensão de uma situação concreta existencial, os conhecimentos científicos fragmentados historicamente se apresentam de forma articulada. 
Figura 03. Base da Rede Temática desenvolvida em Olivença/BA

TEMA GERADOR - OLIVENÇA: EU VIVO EM UM PARAISO ESQUECIDO

Isso é muito comum dizer que o lixo é um problema, mas é quem é que joga o lixo? Alguém parou para pensar? 0 comaroda acha que quando ele coloca o lixo na porta dacasa dele, ele resol começou o problema do lixo. Ele gerou um lixo e acha que a prefeitura que tem que resolver. $E$ ainda acha que a préétura tem que resolver do jeito dele e não do jeito que a prefeitura ou a proposta da gestão resolveu fazer (Pp1)

Superlotaçāo é em todos lugares, não existe ōnibus vazio em horário de pico [ ] 0 grande problema do transporte coletivo éque eles querem o horário que eles saem, como o próprio ônibus é coletivo (Pp3)

Ahh $\in$ com relação assim, a questão ambiental a senhora á ouviu falar do areal aqui? (Pq3)

É... é um problema também, aquele de lá debaixo, é um problema com a comunidade indigna, ai já teve, teve... Confronto por causa desse areal, o índio já perdeu a perna, por causa de... mas agora tá tranquilo também, já resolveram o problema (M2)

\section{7}

$\mathrm{O}$ areial tá causando desmatamento? Será que destroi as nascentes? (Pq3)

Nas nascentes sempre destrói né... que é tirando a........ né...mas num deixa de destruir, mas tá legal, eles lá dá como legal...quem sou eu pra... de que é ilegal...risos (M5)

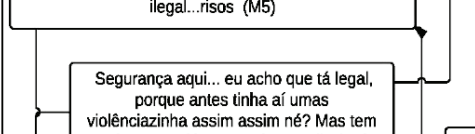
muito tempo já, agora tá tranquilo (M1)

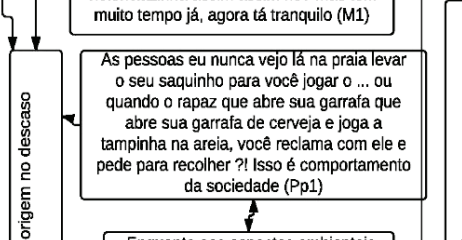

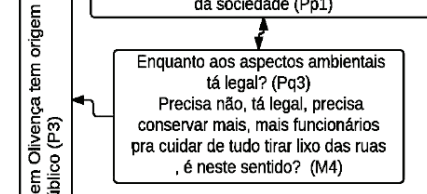

Porque eles (banhistas) ficaram

Porque eles (banhistas) ficaram
lá depois do Jubiabá ali, lá nåo tem salva vida, então, eles em vez de vim pro ambiente que tem salva vida, aí sempre ficam recuado, então, morreu um rapaz, desapareceu, não sei se encontrou encontrou.... Ontem tambern afogou uma ciranca ali, a também, que tem de ter mais cuidado, né. (M3)

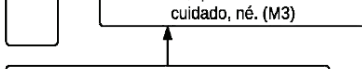

Desmatamento da terra e extração desenfreada de areia. Esse desequilibrio atinge toda nossa comunidade interferindo na perda das nascentes [...]

Toda comunidade tem conhecimento, mas não há nada a fazer (Al3).
Na sirihyba não há caso de poluiçâao porque existe moradores muito compromissados com a natureza, eu por exemplo faço retirada do lixo na praia do sirihyba e limpo o rio para as pessoas tornarem banho tranquilos. O que afeta só $e$ desmatamento, a retirada de areia, isso afeta muito. Eu como sou índio, tenho que sempre ajudar com a preservação da natureza (Al4).

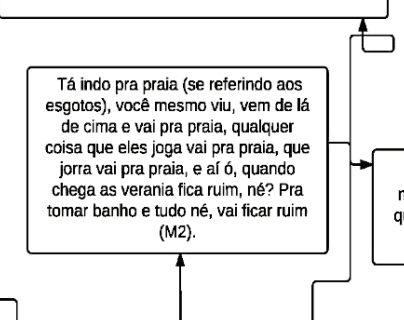

Tá indo pra praia (se referindo aos gotos), você mesmo viu, vem de de cima e vai pra praia, qualquer coisa que eles joga vai pra praia, que jorra vai pra praia, $e$ aĺ $́$, quando chega as verania fica ruim, né? Pra (M2).

É, porque ele (esgotos) vem de lá, nó? pousadas dali de cima, pousadas dalle desse.Manacá, Vila Verde, aí eles num fizeram um "negoço" pra ficar lá, porque tem deles que tem que faze uma fossa muito grande pra ficar lá mesmo, né? Mas eles bota pra não ter trabalho de limpar e escoa pra, pra, tem canos, né? Aí,né (M1)

Será que a gente pode filmar ali? Será que nå filmar alí? Será que não
tem problema não? (referindo-se aos esgotos lançados no rio) (Pq3)

Você tirar toto? Que, vai lá e tira, nada, vocé tó fazendo seu trabalho....agora a gente nåo vai porque, pra não dizer, que a gente tá, que a gente tá, né? (M1)

E a população faz alguma
coisa? (referindo-se a coisa? (referindo-se a manifestaçăo em relação ao areal) (Pq3)

E a população vai fazer 0

que minha filha? (M1)

que minhailina? (M1)

aqui, o único pessoal que

se envolve é os índios (M2)

\section{Mas com relaçåo a extraçåo}

areia, aqui tá. ( $(\mathrm{Pq} 2)$

Aareia foi eles lá mesmo, que diz que tem vez que o dono lá embarga, né

de tirar areia e depois torna a

continuar e fica assim nessa briga né? Sempre fica, é entre eles lá mesmo né? Eu não tenho nada a ver (M2)
O Indice de poluiçăo aqui é zero, zero, zero, com todos esses problemas que nós tá tendo nas matas aí, mas o índice de poluiçăo ainda é zero, por que nós temos a quantidade de salito muito

forte ainda, então problemas respiratórios problema de asma o salito cura (M3)

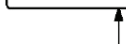

A falta de saneamento básico nunca irá mim afetar. Mas, o mar que eu tomo banho pode sim mim derrubar (Al5)

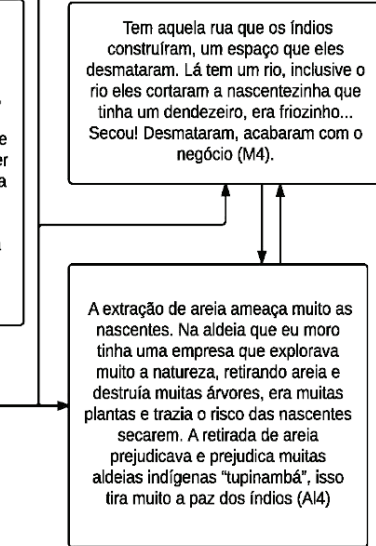

Fonte: Almeida (2018, p. 102) 
Figura 04. Topo da Rede Temática desenvolvida em Olivença/BA

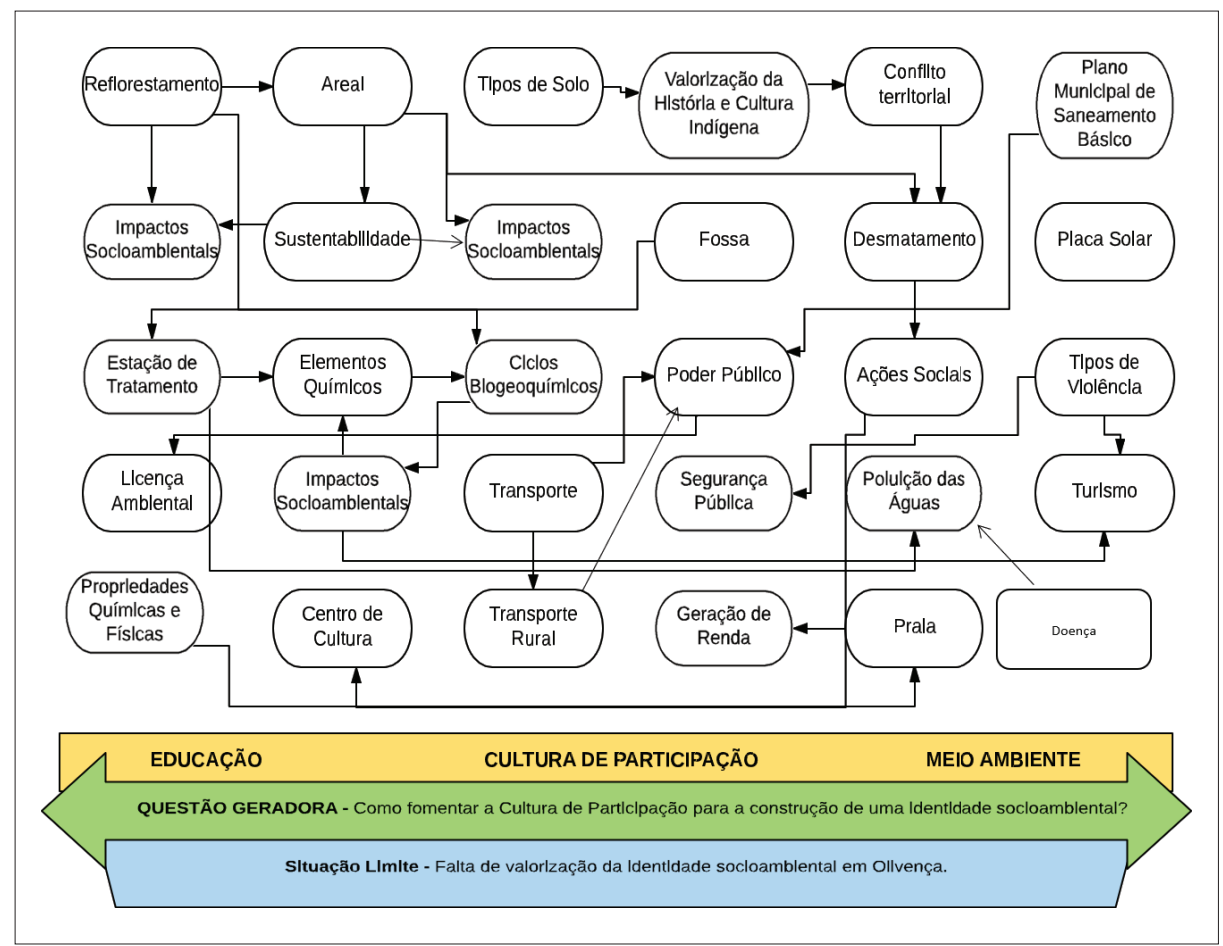

Fonte: Almeida (2018, p. 103).

Diante das necessidades/demandas sociais dos moradores de Olivença, os educadores e pesquisadores selecionaram três elementos, considerados pilares fundamentais do topo da Rede: Educação, Cultura de Participação e Meio Ambiente, por compreenderem que são essenciais para o entendimento e enfrentamento das situações-limites, compreensões limitadas e contradições sociais, expressas na base da Rede.

A seguir serão apresentados os propósitos dos professores e pesquisadores evidenciados durante a construção da Rede Temática, especificamente no topo da Rede, tendo como base os propósitos educacionais definidos por Strieder (2012), ${ }^{5}$ quais sejam o desenvolvimento de: percepções entre o conhecimento científico e o contexto de vida dos educandos, questionamentos sobre a realidade e compromisso social diante das problemáticas vivenciadas pelos alunos.

\section{a) Desenvolvimento de percepções}

Conforme a Matriz de Referência CTS (STRIEDER; KAWAMURA, 2017), o desenvolvimento de percep̧̧ões, que corresponde ao propósito educacional de mais baixa criticidade, consiste no estabelecimento de relações e/ou percepções entre o conhecimento científico escolar e o cotidiano do aluno. Para as autoras, nessa categoria não necessariamente há preocupação em questionar os conteúdos curriculares já preestabelecidos, a ênfase é em como ensinar estes conteúdos e como fazer para que o aluno perceba seu significado. 
O propósito de desenvolvimento de percepções entre o conhecimento científico escolar e o contexto de vida dos educandos foi expresso em algumas falas de professores e pesquisadores, participantes do processo formativo desenvolvido em Olivença, e compreende diversas discussões, por exemplo, acerca do ensino da cultura indígena para que haja a compreensão e valorização destes povos e ensino de questões técnicas dos areais, para que os educandos compreendam os procedimentos sobre a extração de areia, conforme extratos a seguir.

Acho que seria interessante também estudarmos a cultura indígena. Certo dia um aluno me falou que não gostava de índios, que achava todos preguiçosos. Eu expliquei que não era bem assim, eles apresentavam outros costumes e outra cultura. Depois o aluno falou: "a partir de hoje eu estou vendo os índios de outra forma", por isso, acho interessante trabalhar a cultura indígena em sala de aula. $O$ que é a cultura indígena? Porque o não conhecimento da história leva a essa desvalorização do povo indígena ( $\mathrm{P} 2$, grifos nosso).

Partindo dos conhecimentos, é preciso conhecer por exemplo, a questão da atividade de extração de areia, entender como é, por que as vezes eles [educandos] não têm noção (P2, grifos nosso).

Para compreender como é feita a extração de areia precisa estudar tipos de solo e composição do solo (PQ1, grifos nosso).

Essas falas expressam a preocupação de alguns educadores e pesquisadores de relacionar os conteúdos programáticos escolares com o cotidiano dos educandos. Dentre os conteúdos que visam essa contextualização, evidenciados no topo da Rede, destacam-se: tipos de solo, estação de tratamento de água e esgoto, propriedades químicas e físicas de alguns materiais e elementos químicos presentes na região. Por meio desses conhecimentos científicos os educandos podem compreender algumas questões de seu cotidiano, relacionadas com as contradições sociais expressas no Tema Gerador. Por exemplo, a realização do processo de tratamento de água e esgoto na região, compreender algumas transformações físicas e químicas que ocorrem na natureza, tipos de solo e sua formação, a relação do solo com a formação de areais e com a presença de minerais na água local, entre outras questões.

Diante da busca pelo desenvolvimento de percepções entre o conhecimento científico e a realidade dos educandos, também houve destaque para a importância da aquisição desse conhecimento para a participação social, conforme o relato a seguir.

Falta a cultura de participação nos moradores. A gente como professor como pode fazer isso? Dá condições para que o aluno tenha conhecimento específico sobre uma determinada questão e isso gere nele uma visão crítica, para que possa depois reivindicar e participar de alguma ação (PQ2). 
PQ2 compreende que a cultura de participação perpassa pela aquisição de conhecimentos científicos, assim faz-se necessário os seguintes questionamentos: a aquisição de informações científicas sobre um dado problema é suficiente para promover o engajamento dos educandos em prol da transformação social? Para agir basta apenas o conhecimento? Em relação a esta questão, Auler e Delizoicov (2015) ressaltam que, em alguns casos, não existem conhecimentos científicos sistematizados necessários para a compreensão dos problemas que afligem a sociedade, visto que as demandas selecionadas pelas agendas de pesquisas da Ciência-Tecnologia são direcionadas por interesses da classe hegemônica. Além disso, Strieder, Bravo-Torija e Gil-Quilez (2017) reconhecem que a apropriação de conhecimentos científicos não é suficiente para compreensão do mundo atual, devido aos riscos e incertezas da Ciência.

Assim, para se desenvolver a cultura de participação, conforme objetiva PQ2, é preciso ir além dos conhecimentos científicos. Nesse sentido, Freire (1987) defende a importância do diálogo entre educador e educando sobre as contradições sociais, a valorização da cultura do aluno e de seus conhecimentos adquiridos por meio da interação homem-homem e homem-mundo; e principalmente o ensino que contemple as aspirações e contradições sociais dos estudantes, de modo a desvelar as desigualdades sociais e despertar a vocação ontológica dos sujeitos em ser mais, isto é, desvelar com os educandos os seus respectivos potenciais para transformar a realidade em prol de sua humanização.

Dessa forma, percebe-se que os educadores têm buscado o desenvolvimento de percepções entre o conhecimento científico escolar e o contexto de vida dos educandos, o que é importante para a compreensão de alguns aspectos da realidade, mas insuficiente de acordo com Freire (1987), para que haja o engajamento dos educandos em prol da transformação da realidade local, que é marcada por desigualdades sociais e possui uma dinâmica estrutural que conduz a dominação de consciências.

\section{b) Desenvolvimento de questionamentos}

Para Strieder e Kawamura (2017), o propósito desenvolvimento de questionamentos busca desenvolver questionamentos sobre questões referentes a Ciência, Tecnologia e/ou Sociedade, bem como as implicações sociais do conhecimento da CT, visando a utilização responsável dos recursos naturais e aparatos tecnológicos e a formação para a cidadania.

No topo da Rede Temática desenvolvida com os educadores da EJA do Colégio Estadual Jorge Calmon, esse propósito se expressa nas discussões sobre os impactos socioambientais causados pelos areais, esgotos lançados nas praias e descarte inadequado do lixo; maneira adequada para se extrair a areia e fazer reflorestamentos; funcionamento das placas solares, estação de tratamento de água e esgoto e suas implicações sociais; riscos dos transportes superlotados etc. Por meio dessas discussões pode-se promover questionamentos de diferentes níveis de criticidade, para que os educandos desenvolvam o senso crítico para discutir sobre problemáticas locais, podendo tomar algumas decisões individuais ou coletivas. 
Destaca-se algumas falas dos professores, em que eles evidenciam a necessidade de se compreender os malefícios causados pelo uso de fossas na comunidade, as implicações negativas dos areais e possíveis alternativas para recuperação das áreas degradadas.

É preciso compreender os perigos das fossas. Aqui na escola mesmo tem fossa e a escola fica ao lado da praia. Nas casas a rede de esgoto é conectada com o rio. Qual a relação das fossas com a poluição do mar? (P2, grifos nosso)

Acho que se a comunidade se conscientizar que houve um prejuízo muito grande, que o problema aconteceu [problema da extração de areia] e o que a gente pode fazer daqui para frente para recuperar, acho que quando a sociedade se conscientizar que a gente não está querendo um embate, que só está querendo recuperar a área degradada que está lá abandonada, até ele [dono do areal] vai querer ajudar (P1, grifos nosso).

As falas de P1 e P2 revelam que os professores começam a refletir sobre a importância do reconhecimento dos problemas que afligem a comunidade de Olivença e também a pensar no desenvolvimento de ações, problematizando a situação vivenciada, indo além da percepção de que existem relações entre o conhecimento científico escolar e o cotidiano dos educandos. Muitas vezes, a comunidade não percebe ou possui uma compreensão limitada sobre os problemas sociais, por exemplo, algumas pessoas ainda pensam que as fossas resolvem os problemas da falta de esgoto. Assim, a discussão sobre os perigos das fossas é de suma importância para o desvelamento da realidade, conforme visa Freire (1987). Alguns professores, a exemplo de P5, também apresentaram a preocupação com o desenvolvimento de questionamentos sobre os interesses envolvidos na produção da Ciência.

Agora que eu sei que a Ciência não está a meu favor, que existe interesses por trás, todo o sistema capitalista, é tudo uma questão histórica, a gente precisa deixar isso bem claro para nossos alunos ( $\mathrm{P} 5$, grifos nosso).

P5 entende que a Ciência não é neutra, que os valores do capitalismo norteiam seu processo de produção, favorecendo as desigualdades sociais. Delizoicov e Auler (2011) realizaram um estudo sobre a dimensão espaço-temporal da CT e evidenciaram que a Ciência é direcionada por valores. Geralmente, os valores que têm norteado a produção da CT são vinculados ao capitalismo, que é caracterizado por atender aos interesses de uma minoria economicamente favorecida, provocando desigualdades sociais e a marginalização da população (ROSO, 2017; AULER, 2018). Dessa forma, no processo de organização curricular, é essencial a discussão sobre o processo de produção da Ciência, visto que as discussões não podem ficar restritas somente a pós-produção, após os produtos já estarem produzidos, para amenizar os impactos negativos. É preciso compreender os interesses envolvidos na produção, as reais causas dos problemas, para poder promover a transformação da realidade, em prol de uma maior equidade social (AULER, 2002; ROSO, 2017). 
A educadora P1 evidencia que no contexto escolar, a melhor forma de encaminhar os problemas provocados pela extração desenfreada de areia é por meio do desenvolvimento de ações para restaurar as áreas degradadas, por entender que apenas discursos sobre as implicações sociais dos areais não obterá êxito, conforme extrato abaixo.

Como eu estou pensando em fazer um projeto, já comecei a questionar com os moradores mais antigos, como era ali antes e tal. A quantidade de nascentes que tinha, tinha tipo um lago, sempre faziam análise a água era mineral, perfeita, de qualidade, poderia até ser engarrafada. Essa água abastecia toda a região, ninguém tinha necessidade da água da EMBASA e agora secou tudo. Conhecer eles conhecem, sabem que destrói, acho que é mais medo mesmo. Por exemplo, eles comentando: "por que os micos agora estão invadindo nossas casas para pegar comida? Porque olha lá não tem mais nada". A gente que subestima, mas eles têm conhecimento sim, agora é aquele negócio eu vou brigar com quem? Olha o poder do cara [dono do areal]. Conversando com as pessoas, foi o que eu percebi, se você for por este lado que é nocivo não vai adiantar, ninguém vai falar nada. Só chega nessas pessoas para conscientizar se você chegar assim, a gente não quer atrapalhar o trabalho deles, a gente está querendo montar um projeto para recuperar essas áreas, para que as nascentes voltem, os animais voltem, que tenha o espaço deles. Eles têm muito medo, até os índios têm medo. Eles não querem que acabe com os areais, eles precisam de emprego, das ações assistencialistas do dono do areal (P1, grifos nosso).

Para P1, a população de Olivença tem conhecimento das implicações e transformações geradas pelo extrativismo exacerbado de areia. No entanto, ela silencia-se diante deste problema por medo, devido às medidas coercitivas exercidas pelos donos dos areais e também devido às oportunidades de emprego ofertadas neste setor. Diante desse contexto, a educadora apresenta um protagonismo, busca estabelecer uma parceria entre a escola e os moradores, pautada no diálogo e na empatia, para juntos desenvolverem um projeto de reflorestamento. Muenchen e Auler (2007) apontam que o desenvolvimento de temas polêmicos que envolvem conflitos/contradições locais é um desafio a ser enfrentado no âmbito de intervenções curriculares na perspectiva CTS. Para Auler (2018), "quando buscamos contribuir para a constituição de um novo corpo político/conceitual, que ajude a construir e iluminar o caminho para outro mundo possível, estamos numa luta contra hegemônica, na qual a margem de manobra é pequena" (p. 121).

No intuito de despertar a cultura de participação dos educandos, um pesquisador insiste na necessidade de se discutir os impactos sociais negativos causados pela extração de areia, por entender que dessa forma é possível promover o reconhecimento deste problema, de forma mais aprofundada, e consequentemente a participação social da comunidade.

É importante estudar sobre solo, porque com certeza [os areais] tem uma consequência muito grande no solo, como isso vai nos atingir? Já que a gente só faz alguma coisa quando vai nos atingir, então vamos saber como é que vai nos atingir para poder agir (PQ3, grifos nosso). 
Ainda nesta perspectiva, alguns pesquisadores e professores sugeriram promover a participação da comunidade em questões sociais por meio da associação dos moradores e ações sociais, contudo não explicaram a natureza dessas ações e em que consistiria.

Talvez, o primeiro passo seja esse formar uma associação de moradores e aí na associação a gente se fortalece (P4, grifos nosso).

Como a gente está falando de identidade e pertencimento, as informações revelam uma postura muito individual dos moradores, está faltando uma discussão mais social, pensei talvez em ações comunitárias, cooperativismo, ações sociais, que seria o que a sociedade pode fazer diante deste contexto (PQ2, grifos nosso).

Como a comunidade não se sente pertencente a este lugar, ela não luta por aquilo, se isso acontecesse dentro da casa dela ela lutaria, aqui não, aqui é minha casa. Então como eles não entendem ainda o local como minha casa, uma das maneiras seria fazer a comunidade se conscientizar dos problemas, se organizar por meio da associação dos moradores. Eles vão perceber que tem poder, quando o povo se une, o gigante acorda, as coisas acontecem. É este obstáculo que a gente tenta superar dentro da sala de aula, mostrar para os alunos que eles podem sim gerar uma transformação. A gente viu as manifestações agora, o que aconteceu [referindo-se as manifestações políticas de 2016], por mais que tem todo um contexto obscuro por trás, mas quando o povo se une, o gigante acorda, as coisas acontecem (PQ3, grifos nosso).

Em análise as discussões tecidas pelos professores e pesquisadores sobre os areais e a necessidade de se promover uma participação efetiva da comunidade, evidenciou-se que em Olivença, atrelado à extração de areia, que oficialmente pode ser considerada uma atividade legal, o que não é o caso de alguns areais na região, existe um conjunto de contradições sociais complexas que aflige a população. Estas contradições sociais devem ser consideradas na prática educativa, quando se almeja uma educação libertadora, em prol da humanização dos sujeitos, conforme defende Freire (1987). Os moradores vivenciam as transformações sociais provocadas pela extração desenfreada de areia, o desaparecimento da fauna, da flora, das nascentes etc. Entretanto, eles são conquistados por meio do assistencialismo dos donos dos areais, como aponta P1. Associado a este contexto, Rocha (2014) denuncia a falta de fiscalização do poder público no processo de extração ilegal de areia em Olivença.

Um dos principais crimes ambientais cometidos por não indígenas dentro da terra indígena é a extração de areia [...] observei com frequência os inúmeros caminhões carregados de areia [...]. Ao longo deste tempo, apenas em uma ocasião presenciei o ICMBio autuando este tipo de delito e apreendendo junto com a Polícia Federal os caminhões do proprietário. Contudo, a apreensão não durou mais do que um mês e, em seguida os mesmos caminhões já tinham retomado as atividades de extração ilegal (ROCHA, 2014, p. 50). 
A autora, em sua tese de doutorado, realizou uma pesquisa etnográfica com os Tupinambás de Olivença e denuncia vários problemas, tais como: extração ilegal de areia nas terras indígenas, falta de fiscalização do poder público e criminalização dos caciques Tupinambás. Durante a Investigação Temática, também se evidenciou que atos coercitivos e violentos são exercidos pelos donos dos areais ${ }^{6}$ contra as pessoas que lutam para combater a exploração desenfreada de areia, especificamente os índios que são os mais engajados nesta luta, e problemas de desemprego na região, o que contribui para que as pessoas fiquem dependentes das atividades de extração de areia.

Diante da complexidade desta problemática, o desenvolvimento das ações propostas pelos professores e pesquisadores como reflorestamento, abordagem do conhecimento científico e a associação dos moradores, sem uma devida ação e reflexão não serão suficientes para transformação dessa situação existencial. Estes moradores encontram-se aprisionados nesta situação, de modo que alguns sujeitos dominados não conseguem desvelar a realidade opressora em que vivem, assim eles tendem a se acomodar diante da opressão e das desigualdades sociais. Para Freire (1987), o educador por si só não consegue promover esta libertação, a qual só é possível por meio da comunhão, do diálogo e do esforço de ambos os sujeitos para compreender a realidade, que deve ser o objeto cognoscível do ensino, que mediatizará as reflexões e ações desenvolvidas nas aulas.

\section{c) Desenvolvimento de compromissos sociais}

O desenvolvimento de compromissos sociais é o propósito mais crítico da Educação Científica e visa a transformação de mundo, o encaminhamento de problemas reais que afligem a sociedade (STRIEDER; KAWAMURA, 2017). Para tal, entende-se que é preciso o reconhecimento da gênese dos problemas, o que não é uma tarefa fácil. No intuito de encaminhar os problemas causados pelos areais em Olivença, especificamente a degradação da natureza, P2 destacou a necessidade de adequações sociais dos areais, ou seja, o redirecionamento dessa atividade em prol do bem-estar social.

O foco não é acabar com os areais, é fazer com que esta atividade seja menos agressiva, tentar recuperar as áreas degradadas, fazer com que os moradores se posicionem. Será que dá para fazer um trabalho de reparação com os alunos? E outra, será que a gente pode estudar sobre a extração de areia e sugerir meios menos agressivos? (P2, grifos nosso).

Essa concepção de P2 está de acordo com a perspectiva mais crítica do parâmetro desenvolvimento tecnológico, presente na Matriz de referência CTS, em que se discute a necessidade de adequações das tecnologias às necessidades sociais. Nessa perspectiva, "a ideia é minimizar os riscos sem abdicar dos benefícios, enfatizando um sistema tecnológico capaz de se adequar a uma sociedade democrática, com características humanas e regionais" (STRIEDER; KAWAMURA, 2017, p. 39), que também é coerente com o Pensamento LatinoAmericano em Ciência, Tecnologia e Sociedade (PLACTS). 
Strieder (2012) defende que o desenvolvimento de compromissos sociais também pode ser promovido por meio da participação no âmbito das políticas públicas. Durante o processo formativo com os professores, esse foi um aspecto destacado por P3, por entender a necessidade de se abordar questões relacionadas às políticas públicas, tais como os licenciamentos ambientais dos areais e o Plano Municipal de Saneamento Básico (PMSB).

Nós temos que fazer com que eles conheçam a realidade, entendam as licenças ambientais, as propostas de amenizar os impactos que eles fizeram e se estão sendo realizadas ou não, isso que a escola pode fazer [...] Ao discutir saneamento básico entra a questão do Poder Público, Estação de Tratamento de Esgoto (ETE) e PMSB (P3, grifos nosso).

P3 entende que a escola precisa desenvolver uma cultura de participação no âmbito das políticas públicas, para tal sugere abordar algumas políticas e leis presentes na região, visto que muitas vezes estas são desconhecidas pelos educandos. Strieder (2012) destaca que na abordagem das políticas públicas o ideal seria a participação da sociedade na definição de seus objetivos, meios para alcançá-los e maneiras para controlar sua implementação. Contudo, deve se reconhecer que a discussão de políticas públicas e leis no contexto escolar já é um passo importante para a formação para a cidadania, pois para participar é preciso conhecer a realidade, saber seus direitos e deveres, para poder se mobilizar para lutar em prol de melhores condições de vida. Um trabalho que apresenta uma iniciativa nesta linha foi realizado por Centa e Muenchem (2016), em que no contexto escolar, a partir de uma demanda social da região, ocorreu um movimento de participação social junto à comunidade e ao poder público, no contexto municipal.

Ainda, sobre este propósito educacional, Strieder (2012) ressalta que por meio de discussões das limitações do conhecimento científico para compreender e resolver os problemas sociais, também pode-se desenvolver compromissos sociais. Os professores não relataram explicitamente sobre a insuficiência da Ciência para resolver/encaminhar os problemas sintetizados no Tema Gerador. Entretanto, os professores selecionaram outros conhecimentos, outras questões, como ações, valores, aspectos culturais etc. que vão além do conhecimento científico, perpassando também outras esferas além da escola, como o poder público municipal e a comunidade, o que requer também outros atores sociais para tomadas de decisões, além das pessoas especializadas cientificamente.

\section{CONSIDERAC̣ÕES FINAIS}

Para a compreensão do Tema Gerador: "Olivença: eu vivo em um paraíso esquecido" os professores e pesquisadores, participantes do processo formativo desenvolvido em Olivença, selecionaram alguns conteúdos, conhecimentos e ações que podem ser desenvolvidas no contexto escolar, na comunidade e no âmbito do poder público municipal. De modo geral, os propósitos educacionais presentes no processo de Redução Temática, especificamente na elaboração do topo da Rede Temática, apresentaram diferentes níveis de criticidade, voltados ao 
desenvolvimento de percepções entre o conhecimento científico e o contexto de vida do educando, questionamentos da realidade e compromissos sociais. Concluise que esses propósitos são importantes a serem considerados na elaboração da Redução Temática, pois podem conduzir o processo de seleção dos conhecimentos e ações a serem desenvolvidas no contexto escolar.

Contudo, as discussões realizadas pelos educadores e pesquisadores durante este processo são muito amplas, devem ser melhor delimitadas para serem inseridas no currículo escolar. Além disso, é preciso aprofundar algumas questões apontadas no Topo da Rede Temática, de modo a compreender o cerne dos problemas. Nesse sentido, delimitou-se algumas considerações sobre a problemática dos areais, tais como: a) é necessário refletir sobre os interesses envolvidos na execução dos areais, para que a população tenha subsídio para analisar se a exploração de areia é uma demanda social ou visa atender aos interesses de uma minoria economicamente favorecida; b) as discussões não podem ficar restritas à pós-execução, pós-extração de areia, somente para amenizar os impactos negativos. É necessário que ocorram no processo de planejamento da extração da areia, na pré-produção, de modo a considerar valores voltados a uma economia solidária, a humanização e o bemestar social; c) é preciso compreender os interesses envolvidos nesta atividade, para poder promover a transformação da realidade, em prol de uma maior equidade social e; d) é necessário discutir as relações entre os areais, a construção civil e a sociedade, para que os educandos não construam uma concepção fatalista deste problema, devido ao destaque que a construção civil possui historicamente.

Essa análise do topo da Rede Temática foi potencializada por meio das discussões presentes na Matriz (STRIEDER, 2012), a qual auxiliou na compreensão mais crítica e ampliada da realidade, possibilitando a identificação de visões limitadas e também a definição/seleção de conhecimentos necessários para compreensão e encaminhamento das contradições sociais. Entretanto, o pesquisador e/ou educador ao utilizar a matriz precisa articular os aspectos CTS que se apresentam numa dimensão global, com as demandas/necessidades locais, identificadas via Investigação Temática. Freire (1987) defende que a articulação local-global é um requisito para uma compreensão crítica da realidade, visto que o mundo se apresenta de forma dinâmica.

Diante dos resultados obtidos no presente trabalho, conclui-se que a Investigação Temática articulada com a Educação CTS, possibilita a obtenção e desenvolvimento de temas de relevância social, em uma perspectiva críticotransformadora, isto é, que perpasse pela compreensão crítica da realidade, relacionando as diversas esferas sociais, políticas, econômicas, ambientais, científicas e tecnológicas e também ações sociais em prol da transformação da sociedade. Assim, a Investigação Temática pode nortear a construção de currículos humanizadores, pautados em demandas sociais. Em conformidade com alguns pesquisadores como Auler e Delizoicov (2015) e Roso e Auler (2016), que têm destacado potencialidades da Investigação Temática, ressalta-se que esta conduz o processo educativo, não permitindo cair num reducionismo teórico-metodológico, nem em uma concepção bancária de educação. A sua realização possibilita a autonomia dos educandos e educadores, a articulação entre os processos de concepção e execução de currículos, a interdisciplinaridade e o engajamento da 
comunidade escolar (educandos, educadores e coordenação) e da comunidade local (moradores), pelo fato de apresentar uma significância social.

\section{REFERÊNCIAS}

ALMEIDA, E. S. A Investigação Temática na perspectiva da articulação Freire-CTS. 2018. Dissertação (Educação em Ciências) - Universidade Estadual de Santa Cruz, Ilhéus, 2018. Disponível em: http://www.biblioteca.uesc.br/biblioteca/bdtd/ 201610055D.pdf. Acesso em: 28 maio 2018.

AULER, D. Interações entre ciência-tecnologia-sociedade no contexto da formação de professores de ciências. 2002. Tese (Doutorado em Educação) - Universidade Federal de Santa Catarina, Florianópolis, 2002. Disponível em: https://repositorio.ufsc.br/handle/123456789/82610. Acesso em: 10 abr. 2018.

AULER, D. Cuidado! Um cavalo viciado tende a voltar para o mesmo lugar. $1^{\mathrm{a}}$ ed. Curitiba: Appris, 2018.

AULER, D.; DELIZOICOV, D. Educação CTS: Articulação entre Pressupostos do Educador Paulo Freire e Referenciais Ligados ao Movimento CTS. In: Las Relaciones CTS en la Educación Científica, 5, 2006, Málaga-Espanha. Atas do V Encontro iberoamericano sobre Las Relaciones CTS en la Educación Científica. Málaga: Editora da Universidade de Málaga, p. 01-09, 2006. Disponível em: http://www.educadores.diaadia.pr.gov.br/arquivos/File/2010/artigos_teses/fisica/ educ_cts_delizoicov_auler.pdf. Acesso em: 10 fev. 2018.

AULER, D.; DELIZOICOV, D. Investigação de temas CTS no contexto do pensamento latinoamericano. Linhas Críticas. v.21, n.45, p.275-296, 2015. Disponível em: http://periodicos.unb.br/ index.php/linhascriticas/article/view/16728. Acesso em: 24 jun. 2018

CARDOSO, Z. Z.; ABREU, R.O. D.; STRIEDER, R. B. Lixo Eletrônico: uma proposta CTS para o ensino médio. Indagatio Didactica, v.8, p. 1611-1626, 2016. Disponível em: http://revistas.ua.pt/ index.php/ID/article/view/3957. Acesso em: 20 mai. 2018.

CENTA, F. G.; MUENCHEN, C. O. Despertar para uma Cultura de Participação no Trabalho com um Tema Gerador. Alexandria - Revista de Educação em Ciência e Tecnologia, v. 9, n.1, p. 263291, 2016. Disponível em: https://periodicos.ufsc.br/ index.php/alexandria/article/view/19825153.2016v9n1p263. Acesso em: 28 jan. 2018.

DECONTO, D. C. S.; CAVALCANTI, C. J. H.; OSTERMANN, F. A Perspectiva Ciência, Tecnologia e Sociedade na Formação Inicial de Professores de Física: Estudando Concepções a partir de uma Análise Bakhtiniana. Alexandria - Revista de Educação em Ciência e Tecnologia, v. 9, n.2, p. 87119, 2016. Disponível em: https://periodicos.ufsc.br/index.php/alexandria/article/view/19825153.2016v9n2p87. Acesso em: 09 mar. 2018

DELIZOICOV, D. Conhecimento, tensões e transições. 1991. Tese (Doutorado em Educação) - Universidade de São Paulo, São Paulo, 1991. Disponível em: http://repositorio.ufsc.br/xmlui/ handle/123456789/75757. Acesso em: 6 jun. 2018.

FONSECA, K. N. Investigação Temática e a Formação Social do Espaço: construção de uma proposta com professores dos anos iniciais. 2017. Dissertação (Mestrado em Educação em Ciências) - Universidade Estadual de Santa Cruz, Ilhéus, 2017. Disponível em: http:/ /www.biblioteca.uesc.br/ biblioteca/bdtd/201511566D.pdf. Acesso em: 07 jul.2018.

FREIRE, P. Pedagogia do oprimido. $17^{\mathrm{a}}$ ed. Rio de Janeiro: Paz e Terra, 1987. 
HUNSCHE, S.; AULER, D. O Enfoque Temático no Ensino de Física: Desafios enfrentados por Estagiários. In: Simpósio Nacional de Ensino de Física, 18, 2009, Vitória. Atas do XVIII Simpósio Nacional de Ensino de Física, Vitória, 2009. Disponível em: http://www.sbf1.sbfisica.org. br/eventos/snef/xviii/sys/resumos/T0469-1.pdf. Acesso em: 11 set. 2018.

MATOS, S. A. Abordagem Ciência, Tecnologia e Sociedade em uma disciplina do curso de especialização em ensino de ciências por investigação. Tese (Doutorado) - Universidade Federal de Minas Gerais, Belo Horizonte, 2014. Disponível em: https://repositorio.ufmg.br/handle/1843/ BUOS-9VEPXJ. Acesso em 05 fev. 2018.

MORAES, R.; GALIAZZI, M.C. Análise Textual Discursiva. 2ª ed. Ijuí: Unijuí, 2011.

MUENCHEN, C.; AULER, D. Configurações curriculares mediante o enfoque CTS: desafios a serem enfrentados na Educação de Jovens e Adultos. Ciência \& Educação, Bauru, v.13, n.3, p.421434, 2007. Acesso em: http://www.scielo.br/ scielo.php?pid= S151673132007000300010\&script= sciabstract\&tlng=pt. Acesso em: 06 mar. 2018.

ROCHA, C. C. "Bora vê quem pode mais": Uma etnografia sobre o fazer política entre os Tupinambá de Olivença (Ilhéus, Bahia). 2014. Tese (Doutorado em Antropologia Social) - Universidade Federal de Santa Catarina, Florianópolis, 2014. Disponível em: https://repositorio.ufsc.br/bitstream/ handle/123456789/128885/ 329719.pdf?sequence=1\&isAllowed=y. Acesso em: 28 ago. 2018.

ROSO, C. C. Transformações na educação CTS: uma proposta a partir do conceito de Tecnologia Social. 2017. Tese (Doutorado em Educação Científica e Tecnológica) - Universidade Federal de Santa Catarina, Florianópolis, 2017. Disponível em: https://repositorio.ufsc.br/ handle/123456789/187060. Acesso em: 10 fev. 2018.

ROSO, C. C., AULER, D. A Participação na Construção do Currículo: Práticas Educativas Vinculadas ao Movimento CTS. Ciências \& Educação, Bauru, v.22, n.2, p.371-389, 2016. Disponível em: http://www.scielo.br/pdf/ciedu/v22n2/1516-7313-ciedu-22- 02-0371.pdf. Acesso em: 05 jul. 2018.

ROSO,C.C.;SANTOS,R.A.;ROSA,S.E.;AULER,D.Currículotemático fundamentadoemFreire-CTS: engajamentodeprofessoresdefísicaem formaçãoinicial.EnsaioPesquisaemEducaçãoemCiências, Belo Horizonte, v. 17, n.2, p. 372-389, maio/ago., 2015. Disponível em: https://seer.ufmg.br/index. $\mathrm{php} /$ ensaio $/ \mathrm{search} /$ authors $/$ view? firstName $=$ Caetano\&middleName $=$ Castro\&lastName $=$ Roso $\&$ affiliation=UFSC\%2FSC\&country=BR. Acesso em: 12 set. 2018

SANTOS, W. L. P. Educação Científica Humanística em uma perspectiva Freireana: resgatando a função do ensino de CTS. Alexandria - Revista de Educação em Ciência e Tecnologia, v.1, n. 1, p. 109-131, mar., 2008. Disponível em: https://periodicos. ufsc.br/index.php/alexandria/article/ view/37426. Acesso em: 23 out. 2017.

SILVA, A. F. G. A construção do currículo na perspectiva popular crítica: das falas significativas às práticas contextualizadas. 2004. Tese (Doutorado em Educação: Currículo) - Pontifícia Universidade Católica de Brasília, São Paulo, 2004. Disponível em: https://tede2.pucsp.br/handle/ handle/22098. Acesso em: 05 jun. 2018.

SOUSA, P.S.; BASTOS, A.P. S.; FIGUEIREDO, P. S.; GEHLEN, S. T. Investigação Temática no Contexto do Ensino de Ciências: Relações entre a Abordagem Temática Freireana e a Práxis Curricular via Tema Gerador. Alexandria - Revista de Educação em Ciência e Tecnologia, v. 7, n.2, p. 155-177, nov., 2014. Disponível em: https:// periodicos.ufsc.br/index.php/alexandria/article/ view/38222. Acesso em: 05 ago. 2018. 
STRIEDER, R. B. Abordagens CTS na educação científica no Brasil: Sentidos e perspectivas. 2012. Tese (Doutorado em Ciências) - Universidade de São Paulo, São Paulo, 2012. Disponível em: https://teses.usp.br/teses/disponiveis/81/81131/tde-13062012-112417/pt-br.php. Acesso em: 20 dez. 2017.

STRIEDER, R. B.; BRAVO-TORIJA, B.; GIL-QUILEZ, M. J. Ciencia-tecnología-sociedad: ¿Qué estamos haciendo en el ámbito de la investigación en educación en ciencias? Enseñanza de las Ciencias, v. 35, n. 3, p. 29-49, nov., 2017. Disponível em: https://www.raco.cat/index.php/ Ensenanza/article/view/329206. Acesso em: 10 nov. 2018.

STRIEDER, R. B.; KAWAMURA, M. R. D. Educação CTS: Parâmetros e Propósitos Brasileiros. Alexandria - Revista de Educação em Ciência e Tecnologia, v.10, n.1, p. 27-56, mai., 2017. Disponível em: https://periodicos.ufsc.br/index.php/ alexandria/ article/view/1982-5153.2017v10n1p27. Acesso em: 12 mai. 2018.

\section{NOTAS}

1 A Abordagem Temática consiste numa "perspectiva curricular cuja lógica de organização é estruturada com base em temas, com os quais são selecionados os conteúdos de ensino das disciplinas. Nessa abordagem, a conceituação científica da programação é subordinada ao tema" (DELIZOICOV; ANGOTTI; PERNAMBUCO, 2011, p. 189).

2 Situações-limite são situações que se apresentam ao povo como freios ao processo de compreensão e transformação da realidade, vistas de forma fatalista, como se fossem determinantes históricas, cuja alternativa seria a adaptação diante dessas situações (FREIRE, 1987).

3 O modelo tradicional/linear de desenvolvimento se pauta na ideia de que o desenvolvimento científico gera desenvolvimento tecnológico, que gera desenvolvimento econômico e, consequentemente, o desenvolvimento social (AULER, 2002).

4 Este grupo é vinculado à Universidade Estadual de Santa Cruz (UESC) e tem desenvolvido propostas curriculares e processos formativos de professores de Ciências, organizados por meio da Investigação Temática, em parceria com escolas e secretarias municipais e/ou estaduais de educação em municípios do Sul da Bahia.

5 Ressalta-se que os propósitos educacionais definidos por Strieder (2012) se referem a educação CTS, assim foi necessário adaptá-los para o contexto educacional mais amplo. Por exemplo, o propósito desenvolvimento de questionamento sobre as relações CTS passou a ser compreendido como questionamento de situações vivenciadas pelos educandos, os demais propósitos continuaram com as mesmas ideias de desenvolvimento de percepção entre o conhecimento científico e o contexto de vida dos educandos e desenvolvimento de compromissos sociais diante das problemáticas vivenciadas.

6 Em vídeos e textos publicados na internet, tupinambás denunciaram a ação de "pistoleiros" numa área conhecida como Areal (por causa da extração de areia), na zona sul de Ilhéus. O local teria sido alvo de uma ordem de reintegração de posse contra os indígenas. Blog do Gusmão, disponível em: http://www.blogdogusmao.com.br/v1/ 2016/01/28/tupinambas-denunciam-acaode-pistoleiros-em-ilheus/

7 A Lei n. ${ }^{\circ}$ 11.445/2007, Lei de Saneamento Básico, obriga as prefeituras a elaborar o PMSB, que consiste em um conjunto de serviços, infraestruturas e instalações operacionais relativo aos processos de: abastecimento de água potável, esgotamento sanitário, manejo de resíduos sólidos e drenagem e manejo das águas pluviais urbanas. Disponível em: http://www.planalto.gov.br/ ccivil_03/_ato2007-2010/2007/lei/111445.htm 
Submetido em 12/02/2019

Aprovado em 29/10/2019

\section{Contato:}

Rua Albino Lopes da Silva, n. 99 - Bairro Cajueiro

CEP 45.300-000 - Amargosa, BA - Brasil 